\title{
Does exam-targeted training help village doctors pass the certified (assistant) physician exam and improve their practical skills? A cross-sectional analysis of village doctors' perspectives in Changzhou in Eastern China
}

Xiaohong Li ${ }^{1}$, Jay J. Shen ${ }^{2}$, Fang Yao ${ }^{3}$, Chunxin Jiang ${ }^{4}$, Fengshui Chang ${ }^{1}$, Fengfeng Hao ${ }^{1}$ and Jun $\mathrm{Lu}^{1 *}$

\begin{abstract}
Background: Quality of health care needs to be improved in rural China. The Chinese government, based on the 1999 Law on Physicians, started implementing the Rural Doctor Practice Regulation in 2004 to increase the percentage of certified physicians among village doctors. Special exam-targeted training for rural doctors therefore was launched as a national initiative. This study examined these rural doctors' perceptions of whether that training helps them pass the exam and whether it improves their skills.

Methods: Three counties were selected from the 4 counties in Changzhou City in eastern China, and 844 village doctors were surveyed by a questionnaire in July 2012. Chi-square test and Fisher exact test were used to identify differences of attitudes about the exam and training between the rural doctors and certified (assistant) doctors. Longitudinal annual statistics (1980-2014) of village doctors were further analyzed.

Results: Eight hundred and forty-four village doctors were asked to participate, and 837 (99.17\%) responded. Only 14.93\% of the respondents had received physician (assistant) certification. Only $49.45 \%$ of the village doctors thought that the areas tested by the certification exam were closely related to the healthcare needs of rural populations. The majority (86. $19 \%)$ felt that the training program was "very helpful" or "helpful" for preparing for the exam. More than half the village doctors (61.46\%) attended the "weekly school". The village doctors considered the most effective method of learning was "continuous training (40.36\%)". The majority of the rural doctors (89.91\%) said they would be willing to participate in the training and $96.87 \%$ stated that they could afford to pay up to 2000 yuan for it.

(Continued on next page)
\end{abstract}

\footnotetext{
* Correspondence: lujun@shmu.edu.cn

'Department of Health Policy and Management, China Research Center On Disability, Innovation Center for Social Risk Governance in Health, School of Public Health, Fudan University, P.O. Box 177, 130 Dong'an Road, Shanghai 200032, China

Full list of author information is available at the end of the article
}

(c) The Author(s). 2018 Open Access This article is distributed under the terms of the Creative Commons Attribution 4.0 International License (http://creativecommons.org/licenses/by/4.0/), which permits unrestricted use, distribution, and reproduction in any medium, provided you give appropriate credit to the original author(s) and the source, provide a link to the Creative Commons license, and indicate if changes were made. The Creative Commons Public Domain Dedication waiver (http://creativecommons.org/publicdomain/zero/1.0/) applies to the data made available in this article, unless otherwise stated. 
(Continued from previous page)

Conclusions: The majority of village doctors in Changzhou City perceived that neither the certification exam nor the training for it are closely related to the actual healthcare needs of rural residents. Policies and programs should focus on providing exam-preparation training for selected rural doctors, reducing training expenditures, and utilizing web-based methods. The training focused on rural practice should be provided to all village doctors, even certified physicians. The government should also adjust the local licensing requirements to attract and recruit new village doctors.

Keywords: China, Village doctors, Rural health, Training, Certified physician, Certified assistant physician, Healthcare workforce,

\section{Background}

Geographic discrepancies, especially urban-rural disparities, in healthcare resources and availabilities exist in China, as in other developing countries. With its economic growth during the past four decades, the Chinese government has introduced a number of measures aiming to narrow these disparities and improve healthcare in rural areas.

Based on the Law on Physicians issued in 1999, the Rural Doctor Practice Regulation [1] was issued in 2004 as a national regulation aiming to improve the quality of the healthcare workforce in rural China. The law stipulates required qualifications and related training programs and curricula for rural doctors who work in the village health clinics of rural China.

Village health clinics are always the first choice of rural residents seeking medical care [2]. They are the bottom of the rural three-tier health care network that consists of county-level health care facilities, township hospitals, and village health clinics [3]. The healthcare workforce in such clinics is composed of all the members working there [4]. The doctors, based on their qualifications, are classified as certified physicians, certified assistant physicians, rural doctors, and health workers [5].

The modern history of the training and qualifications of village doctors goes back more than 60 years, to the founding of the People's Republic of China in 1949. That year, regulations related to qualifications for village doctors began to be created. They have evolved through four successive phases since then. The first phase was the "prebarefoot doctor period (1949-1964)" [6]. When the Republic was established, the health system in the country was not well-developed, and the health system in rural China was especially weak. In 1951, the government put forward the Protocol of Specific Implementation Measures for Establishing Rural Health Organizations. It allowed some literate young people to be recruited to work at village health clinics after they received 2-6 months of medical training [6]. During this period, the focus was on establishing the village-level healthcare infrastructure, and the standard for being becoming a village doctor was low.

The second phase was the so-called "barefoot doctor boom period (1965-1980)" [6]. During this time, the concept of "barefoot doctor" was developed and, as a result, both the quantities and the quality of physicians were gradually improved. One was required to be trained for 3 months per year for 3 years before becoming a barefoot doctor. The number of these doctors grew to 1.46 million during this period, and they played a very important role in delivering healthcare in rural China.

During the third period (1981-1998), the "barefoot doctors" became "rural doctors." Rapid economic growth led to a change from a "need for a doctor" to a "need for a good doctor." In 1981, the government implemented a required exam specifically designed for barefoot doctors. Those who passed the exam received the certificate of rural doctor; those who failed only received the certificate of village health worker. The term "barefoot doctor" was no longer used.

"Rural doctors" have become "certified (assistant) physicians" during the fourth period (1999-present). The 1999 Law on Physicians states that rural doctors can pass the national exams to become certified physicians or certified assistant physicians [7]. A certified assistant physician, differing from a certified physician, can provide care at the village health clinic or the township hospital independently, or provide care at a higher-level hospital under the supervision of a certified physician. In addition, a certified assistant physician who has worked for several years may take the exam to become a certified physician. Some major national laws and regulations are listed in Fig. 1.

In 2004, the Rural Doctor Practice Regulation [1] was passed as a supplement to the 1999 law, stipulating that "in principle, only certified (assistant) physicians can be licensed as doctors at the village health clinics" and encouraging "the existing rural doctors to take the exam and become certified (assistant) physicians." More recently, the National Rural Doctor Education Plan (2010-2020) has set a goal that "the majority of village doctors should have the qualifications of certified (assistant) physicians by 2020" [8]. The Plan points out that the local government may provide physician-examtargeted training for rural doctors who lack the qualifications of certified (assistant) physicians. Based on national statistics, however, nearly $70 \%$ of village doctors remain rural doctors in 2014 [5], indicating that it is proving to be a challenge to reach the goal of the Plan. 


\begin{tabular}{|c|c|c|}
\hline $\begin{array}{l}\text { Law on Physicians, } \\
\text { issued in } 1999\end{array}$ & $\begin{array}{c}\text { Rural Doctor } \\
\text { Practice Regulation, } \\
\text { issued in } 2004\end{array}$ & $\begin{array}{l}\text { Rural Doctor } \\
\text { Education Plan } \\
\text { (2010-2020) }\end{array}$ \\
\hline $\begin{array}{l}\text { To carry out exam } \\
\text { system of certified } \\
\text { physician } \\
\text { - Rural doctors can } \\
\text { take part in the } \\
\text { exam } \\
\text { - The state council } \\
\text { will constitute } \\
\text { special regulation } \\
\text { for rural doctors }\end{array}$ & $\begin{array}{l}\text { - In principle, only } \\
\text { certified (assistant) } \\
\text { physicians can be } \\
\text { recruited } \\
\text { - Whether the non- } \\
\text { certified (assistant) } \\
\text { physicians can be } \\
\text { recruited depends } \\
\text { on local province- } \\
\text { level government }\end{array}$ & $\begin{array}{l}\text { Majority of village } \\
\text { doctors should have } \\
\text { qualification of } \\
\text { certified (assistant) } \\
\text { physicians by } 2020 \\
\text { Local government } \\
\text { may provide exam - } \\
\text { targeted training for } \\
\text { the rural doctors } \\
\text { without qualification }\end{array}$ \\
\hline
\end{tabular}

Fig. 1 Important policies related to quality of village doctors since 1999

It is of great interest from the policy and public health perspectives whether and to what extent the Rural Doctor Practice Regulation and related certification exam training is helpful in encouraging and preparing rural doctors to become certified physicians. Furthermore, it is important to know whether the certification exam and the related training programs are beneficial to village doctors in regard to meeting the healthcare needs of rural residents.

Studies have shown that the quality of village doctors in rural China remains low, even after the implementation of the Rural Doctor Practice Regulation. Clayton and colleagues (1993) reported that inadequate sterilization during practice was common among village doctors, and that they often didn't give adequate advice to patients who may carry infections [9]. Studies pointed out that the percentage of antibiotic prescriptions, especially intravenous injections, was very high in rural China $[10,11]$. The literature suggested that over-prescribing antibiotics was very common [12], and the clinical competencies of village doctors needed improvement [13].

The literature has shown that training targeting the certified (assistant) physician exam for the graduating class of undergraduate medical students is helpful [14, 15]. However, very few studies have looked at examtargeted training for village doctors in China, probably due to the fact that it has only been several years since the National Rural Doctor Education Plan (2010-2020) initiative began. Li and colleagues studied routine traditional training of village doctors in China and found that the training status and needs of rural doctors in China were disjointed [16]. Zhang and colleagues pointed out that "web-based training could be a novel pathway" [17] to remedy this deficit. Table 1 "what is already known" and "what this study adds" to this subject.

\section{Methods \\ Study design and data}

This study collected data from a cross-sectional survey being conducted in July, 2012, in Changzhou City in the eastern province of Jiangsu, China. The survey was part of a study on the health workforce in village health clinics. Another part of the study dealing with the shortage of village doctors and their job satisfaction can be found elsewhere [18]. Changzhou is a prefecture-level city. While per capita GDP in 2014 was 46,629 yuan in the whole mainland, that of Jiangsu province was 81,874 yuan, ranking it fourth among the 31 provinces [19]. The per capita GDP of Changzhou in 2014 was 104,423 yuan, ranking it fourth among the 13 prefecture-level cities in Jiangsu province [20]. Three of the four rural counties/districts in Changzhou were selected for this study. All the 844 village doctors in 363 village health clinics were asked to participate, and 837 (99.17\%)

Table 1 "What is already known" and "what this study adds"

\begin{tabular}{|c|c|}
\hline What is already known: & What this study adds: \\
\hline $\begin{array}{l}\text { \Many studies show low quality of health services } \\
\text { provided by village doctors. }\end{array}$ & $\begin{array}{l}\checkmark \text { This study shows low percentage of certified (assistant) physicians based on national } \\
\text { statistics and field survey data in Changzhou. }\end{array}$ \\
\hline $\begin{array}{l}\checkmark \text { Some studies are focused on shortage of and ageing } \\
\text { in village doctors. }\end{array}$ & $\begin{array}{l}\checkmark \text { This study shows the status of participation of exam-targeted training and out-of-pocket } \\
\text { expenditures. }\end{array}$ \\
\hline $\boldsymbol{\sim}$ Very few studies are on exam-targeted training. & $\begin{array}{l}\boldsymbol{V} \text { This study provides suggestions on the content and methods of training of the village } \\
\text { doctors. }\end{array}$ \\
\hline
\end{tabular}


completed the questionnaire. In this study, "village doctors" refers to all persons working at village health clinics. They were asked about their qualifications and attitudes pertaining to the special exam-preparation programs for certified (assistant) physicians.

We also analyzed the quantity and percentage of village doctors based on longitudinal data in annual statistic books [19]. In China, village doctors consist of certified physicians, certified assistant physicians, rural doctors, registered nurses, and village health workers, depending upon their qualifications. Those who passed the exam to become rural doctors but did not take or pass both exams to become certified physicians and certified assistant physicians are termed rural doctors. Those termed village health workers are former barefoot doctors who did not pass the exam for rural doctors. Those who passed the exam for registered nurses were certified registered nurses.

The investigation was carried out in 2012 by researchers from Fudan University with help from the local municipal health bureaus, which provided the full list of the village doctors in their area. Each village doctor completed a structured questionnaire. Questions that were related to this paper consisted of: general demographic information, qualifications, reasons for failing the exam, whether the exam and exam-targeted training was helpful in their daily work, and the cost they were willing to pay for exam-targeted training (Additional file 1).

In addition to surveying village doctors, we also collected routine data about the village clinics from the annual health statistic books of 1980 to 2014. The routine data included the number of the village-level health workforce in China (called "village doctors" in this paper) and the percentage of village doctors according to their qualifications.

\section{Data analysis}

The survey data was entered by EpiData 3.1 and analyzed using SPSS20. Data from the annual health statistic books were analyzed using Microsoft Excel 2013.

\section{Results}

\section{Number of village doctors in rural China}

As presented in Table 2, the number of total village doctors and number of certified (assistant) physicians increased in rural China. Though the percentage of certified (assistant) physicians gradually increased from 2005, it remained low in 2014 (20.84\%). All the percentages of certified (assistant) physicians in eastern, central, and western rural China are low.

\section{Qualifications of village doctors in Changzhou}

The percentage of village doctors with different qualifications is presented in Table 3. All 844 village doctors were asked about their qualifications; 837 (99. $17 \%)$ responded. Only $125(14.93 \%)$ of the 837 village doctors were certified physicians or certified assistant physicians. Only 125 (34.44\%) of the 363 village health clinics had certified (assistant) physicians. The youngest village doctors (20-39 years) had the highest percentage of certified (assistant) physicians. Only 79 (9.46\%) village doctors had an education level of college or higher, and $51.90 \%$ of the village doctors with an education level of college or higher were certified (assistant) physicians. However, having participated in the training was not correlated to the percentage of qualifications statistically (chi square test, $p=0.624$ ).

\section{Attitudes of village doctors about the exam}

All the 844 village doctors knew about the exam, and 748 (88.63\%) had taken it. We asked those who had done so

Table 2 Number of village doctors and percentages with different qualifications (2005-2014)

\begin{tabular}{|c|c|c|c|c|c|}
\hline \multirow[t]{2}{*}{ Year } & \multirow[t]{2}{*}{ Total } & \multicolumn{4}{|c|}{ Percentages with different qualifications (\%) } \\
\hline & & Certified (assistant) physicians & Rural doctors & Nurse & Village health workers \\
\hline 2005 & $1,020,395$ & 10.18 & 84.69 & 0.00 & 5.13 \\
\hline 2008 & $1,127,531$ & 10.61 & 83.22 & 2.20 & 3.97 \\
\hline 2009 & $1,253,705$ & 14.24 & 79.4 & 1.93 & 4.43 \\
\hline 2010 & $1,292,410$ & 13.41 & 79.84 & 2.11 & 4.65 \\
\hline 2011 & $1,350,222$ & 14.31 & 78.55 & 2.26 & 4.88 \\
\hline 2012 & $1,371,592$ & 16.97 & 74.58 & 3.23 & 5.22 \\
\hline 2013 & $1,457,276$ & 19.99 & 68.93 & 5.83 & 5.25 \\
\hline 2014 & $1,460,389$ & 20.84 & 67.50 & 6.70 & 4.96 \\
\hline Eastern & 504,990 & 22.55 & 67.40 & 7.06 & 2.98 \\
\hline Central & 546,449 & 22.01 & 66.21 & 7.08 & 4.70 \\
\hline Western & 408,950 & 17.16 & 69.33 & 5.75 & 7.77 \\
\hline
\end{tabular}

aData are from the "National Health and Family Planning Health Statistic Yearbook (2013-2015)." The percentages in 2014 are listed according to Eastern, Central, and Western China 
Table 3 Percentage of village doctors with different qualification

\begin{tabular}{|c|c|c|c|c|c|}
\hline \multirow[t]{2}{*}{ Variable } & \multirow[t]{2}{*}{$\mathrm{N}$} & \multicolumn{3}{|l|}{ Percentage of qualifications (\%) } & \multirow[t]{2}{*}{ chi-square test $^{t}$} \\
\hline & & Certified (assistant) physicians & Rural doctors & Village health workers & \\
\hline Total $(n=837)^{\mathrm{a}}$ & 837 & 14.93 & 84.35 & 0.72 & \\
\hline Age group $(n=828)^{\mathrm{a}}$ & & & & & $<0.001$ \\
\hline 20-39 years & 213 & 28.64 & 69.01 & 2.35 & \\
\hline $40-49$ years & 191 & 8.90 & 91.10 & 0.00 & \\
\hline $50-59$ years & 252 & 7.93 & 92.06 & 0.01 & \\
\hline 60 - years & 172 & 15.11 & 84.30 & 0.59 & \\
\hline \multicolumn{6}{|l|}{ Education $(n=835)^{\mathrm{a}}$} \\
\hline College or higher & 79 & 51.90 & 48.10 & 0.00 & $<0.001$ \\
\hline Medical vocational school & 364 & 12.64 & 85.99 & 1.37 & \\
\hline High school & 167 & 9.58 & 89.82 & 0.60 & \\
\hline Middle and primary school & 225 & 9.78 & 90.22 & 0.00 & \\
\hline \multicolumn{6}{|l|}{ Working Years $(n=820)^{a}$} \\
\hline $0-9$ years & 32 & 34.38 & 62.50 & 3.13 & $<0.001$ \\
\hline 10-19 years & 256 & 21.48 & 76.95 & 1.56 & \\
\hline $20-29$ years & 150 & 6.67 & 93.33 & 0.00 & \\
\hline 30-39 years & 228 & 11.40 & 88.16 & 0.44 & \\
\hline 40- years & 154 & 13.64 & 86.36 & 0.00 & \\
\hline \multicolumn{6}{|l|}{ Participated in training } \\
\hline Yes & 384 & 14.06 & 84.64 & 1.30 & 0.624 \\
\hline No & 312 & 15.38 & 83.65 & 0.96 & \\
\hline
\end{tabular}

${ }^{a}$ Numbers of actual responses

${ }^{\mathrm{b}}$ Factors for qualifications were evaluated by chi-square test, combining the percentage of rural doctors and that of village health workers

about their opinions of the exam. As shown in the Table 4, 93.72\% of the village doctors stated that the exam theoretically helped improve their medical knowledge level. However, when it came to the question of "whether the exam was related to the actual health needs in rural areas," only $49.45 \%$ of the village doctors answered "Yes."

Among the 748 village doctors who had taken the exam, $625(83.56 \%)$ did not pass; the related reasons were listed in Table 5. Leading reasons for failure were: "The written test was too difficult;" they were "too old to study;" and they were "lacking targeted training."
Participants' attitudes about the training

Among the 696 responding village doctors, 384 (55.17\%) stated that they had attended the special exam-targeted training, whereas 312 (44.83\%) had not. Those who had attended were asked about their opinions of the training (Table 6), and 3.59 and $52.60 \%$ of the respondents pointed out that the training was "very helpful" or "helpful," respectively. As to the frequency of the training, the majority of the village doctors had attended the weekly school, however, they considered that the most effective way of training was "continuous training in school."

Table 4 Opinions of the exam among village doctors with different qualifications $(n=748)$

\begin{tabular}{lccc}
\hline Questions & Rural doctors (\%) & Certified (assistant) physicians (\%) & Total (\%) \\
\hline $\begin{array}{l}\text { The exam impels village doctors to improve medical knowledge level theoretically* } \\
\text { Yes }\end{array}$ & 93.92 & 92.66 & 7.34 \\
No & 6.08 & & 93.72 \\
Relationship between the exam and the actual health needs in rural areas** & & 6.28 \\
Very closely & 0.95 & 4.34 & 3.78 \\
Closely & 39.05 & 36.98 & 45.67 \\
A little closely & 39.05 & 13.96 & 35.43 \\
Not closely & 20.95 & & 15.12 \\
\hline
\end{tabular}

*Chi square test, $p>0.05$ (two-tailed)

**Fisher exact test, $p>0.05$ (two-tailed) 
Table 5 Reasons for failure among the village doctors who failed the exam $\left(n=613^{\mathrm{a}}\right)$

\begin{tabular}{lll}
\hline $\begin{array}{l}\text { The most important reasons for failing } \\
\text { the exam }\end{array}$ & Numbers & Percentage (\%) \\
\hline Written test was too difficult & 217 & 35.40 \\
Too old to study & 195 & 31.81 \\
Technical test was too difficult & 23 & 3.75 \\
Lacking targeted training & 65 & 10.60 \\
Not meeting the prerequisite for exam & 56 & 9.14 \\
Too busy to study & 35 & 5.71 \\
Not paying much attention to the exam & 5 & 0.82 \\
Other & 17 & 2.77 \\
Total & 613 & 100.00 \\
\hline
\end{tabular}

${ }^{a}$ Number of actual responses

Further, 6.51 and $9.90 \%$ of the village doctors pointed out that the most effective way for them to study was "by internet" and "on one's own," respectively. Finally, $55.20 \%$ paid less than 2000 yuan for the training, while $44.80 \%$ paid more than 2000 yuan.

\section{Non-participants' attitudes about the training}

As shown in Table 7, according to the 312 village doctors who did not participate in the training, the leading cause of lack of participation was that they felt they were too old.

\section{Experiences and attitudes toward training according to qualifications}

As shown in Table 8, all the village doctors, including both certified (assistant) physicians and rural doctors, felt the training was essential for passing the exam. They believed that the government should be mainly responsible for the expenses of the training. The majority of the rural doctors $(89.91 \%)$ were willing to participate in the training in the future and $96.87 \%$ stated that they could afford up to 2000 yuan for the training.

\section{Discussion}

Major problems in the exam and exam-oriented training Our findings indicated that the percentage of certified (assistant) physicians among village doctors in Changzhou was below 20\%, far from reaching the goal of "the majority of village doctors should have the qualifications of certified (assistant) physicians by 2020" that has been set by the government. More than $80 \%$ of the doctors did not pass the exam, and only about half of them felt that the exam was closely related to the actual health needs of rural residents. A little over half of the village doctors attended the exam preparation program, more than $85 \%$ of whom think the program was helpful. The majority of the non-certified (assistant) physicians (90\%) were willing to participate in the exam-preparation program and were willing to pay fees up to 2000 yuan.
Table 6 Opinions about training among village doctors participants $(n=384)$

\begin{tabular}{|c|c|}
\hline Viable & Percentage (\%) \\
\hline \multicolumn{2}{|l|}{ Who organized the training } \\
\hline Township & 31.51 \\
\hline County & 46.61 \\
\hline Prefecture-level city & 18.23 \\
\hline Province & 3.65 \\
\hline \multicolumn{2}{|l|}{ The place of training } \\
\hline Township & 47.40 \\
\hline County & 34.90 \\
\hline Prefecture-level city & 17.70 \\
\hline \multicolumn{2}{|l|}{ Helpfulness in preparing for the exam } \\
\hline Very helpful & 33.59 \\
\hline Helpful & 52.60 \\
\hline A little helpful & 11.46 \\
\hline Not helpful & 2.35 \\
\hline \multicolumn{2}{|l|}{ Frequency of training ${ }^{a}$} \\
\hline Having attended weekly school & 61.46 \\
\hline $\begin{array}{l}\text { Having attended continuous training for weeks in } \\
\text { school }\end{array}$ & 35.16 \\
\hline Having attended monthly school & 14.32 \\
\hline \multicolumn{2}{|l|}{ The most effective way of training } \\
\hline Continuous training for weeks in school & 40.36 \\
\hline Weekly school & 29.95 \\
\hline Monthly school & 11.98 \\
\hline On one's own & 9.90 \\
\hline By internet & 6.51 \\
\hline Other & 1.30 \\
\hline \multicolumn{2}{|l|}{ The major content of training ${ }^{a}$} \\
\hline Basic medical knowledge & 82.29 \\
\hline Clinical medicine & 91.93 \\
\hline Preventive medicine & 79.95 \\
\hline Practical operation & 79.95 \\
\hline \multicolumn{2}{|l|}{ Autonomy of attending the training } \\
\hline Required by the township hospital & 70.57 \\
\hline Attending the training voluntarily & 29.43 \\
\hline \multicolumn{2}{|l|}{ Out-of-pocket expenses of the latest training (yuan) } \\
\hline $0-499$ & 13.80 \\
\hline 500-999 & 25.78 \\
\hline 1000-1999 & 15.62 \\
\hline 2000-2999 & 8.07 \\
\hline 3000-3999 & 5.21 \\
\hline 4000-4999 & 9.90 \\
\hline 5000-9999 & 15.89 \\
\hline $10,000-15,000$ & 5.73 \\
\hline
\end{tabular}

${ }^{\mathrm{a}}$ More than one response possible 
Table 7 Reasons village doctors did not take part in the training $(n=312)$

\begin{tabular}{ll}
\hline Reasons & Percentage (\%) \\
\hline "I am too old, and I give up the exam and training." & 46.59 \\
"The training place is too far, because there is no & 20.07 \\
training in the local township." & \\
"I am too busy to participate in the training." & 14.77 \\
"The costs of the training are too expensive." & 9.85 \\
"The exam is so difficult, and I will never pass the exam. & 8.72 \\
So I gave up the training." & \\
\hline
\end{tabular}

However, we found that the training is of limited use in increasing the percentage of certified (assistant) physicians in village clinics who pass the certification exam. There were two possible explanations. First, the percentage of those participating in the training was low, due to the fact that many village doctors thought they were too old to become certified. Barriers in attending the training program, such as inconvenient locations and high fees, only worsened the problem of low enrollment. Second, some village doctors left their village clinics after they became a certified physician, because working at village clinics was not as appealing as working in healthcare settings at higher levels [18]. It is challenging to keep certified assistant physicians at village clinics [21].

\section{Needs for local government actions}

Our results showed that only about $1 / 5$ of village doctors were certified (assistant) physicians in eastern China. The percentage of certified (assistant) physicians in Changzhou was even lower than that in eastern China, which is consistent with the literature stating that few village doctors leave village clinics in more economically developed areas [18]. It is important to note that the national policy of public health equalization, which began implementation in 2009, has significantly increased the tasks and workload of village doctors, which, in turn, aggravates the problem of the shortage of village doctors [18, 22, 23].

China is facing a dilemma between quantity and quality, resulting from the public health equalization policy. On the one hand, more village doctors are needed to implement the policy of basic public health equalization; on the other hand, the Law on Physicians and the Rural Doctor Practice Regulation set strict requirements for the qualifications for becoming village doctors, which seem to be barriers to converting or recruiting more village doctors.

To resolve this dilemma, it may be necessary to rethink the tasks of village health clinics. In general, they can be divided into two categories: clinical services being provided by the certified (assistant) physicians or other clinical staff, and administrative tasks that can be done by non-clinical staff. Many of the administrative tasks include data entry into computers and contacting patients for follow-up on chronic disease management. Nevertheless, village doctors currently are responsible for all these types of administrative work, which occupies a lot of their time that otherwise could be used to provide clinical services. It appears that a dual personnel model could work more efficiently than does the current system. That is, the certified (assistant) physicians or rural doctors are responsible for the clinical services, whereas non-clinical staff may be hired to take care of administrative tasks. The government may issue minimum qualifications for administrative staff to work at village health clinics.

The Rural Doctor Practice Regulation (2004) stipulates that "in order to meet the need for human resources...the local province-level government can formulate specific regulations of licensing based on the local conditions" [1]. In other words, the local government can determine the qualifications of

Table 8 Attitudes about training among village doctors of different qualifications (\%)

\begin{tabular}{lll}
\hline Item & $\begin{array}{l}\text { Certified (assistant) physicians } \\
(n=105)(\%)\end{array}$ & Rural doctors $(n=575)(\%)$ \\
\hline Have participated in the training* & 52.94 & 55.35 \\
Yes & 47.06 & 44.65 \\
No & 95.24 & 86.96 \\
The training is essential for the exam.* & 73.33 & 66.09 \\
The government should be mainly responsible for & - & 89.91 \\
the expenses of the training. & - & - \\
Willing to participate in the training in the future & - & 45.21 \\
Maximum out-of-pocket payment for the training (yuan) & - & 26.09 \\
0-499 & - & 25.57 \\
500-999 & - & 3.13 \\
1000-1999 & - & \\
2000-5000 & & \\
\hline
\end{tabular}

${ }^{*}$ Chi square test, two-tailed, $P>0.05$ 
workers at village clinics. It seems clear that in order to alleviate the problem of doctor shortages in rural areas, local governments may need to revise their current rules and policies for staffing village clinics. More specifically, it may want to allow village health clinics to recruit non-clinical personnel. Currently, in many provincial governments, especially in more economically developed areas, such as Zhejiang [24] and Jiangsu [25], being a certified (assistant) physician is a prerequisite to obtain a license at village health clinics. In contrast, less economically developed provinces, such as Shanxi [26] and Jiangxi [27], allow persons with certain clinical training but who are not certified (assistant) physicians, yet, to practice as village doctors at village clinics. It should be feasible for more-developed provinces to learn from lessdeveloped provinces in this regard in order to solve the doctor-shortage problems in their own rural areas (Fig. 2). Meantime, they should also provide guidelines and qualifications for hiring health workers for village clinics.

\section{Meeting the different training needs of village doctors}

In terms of the goals of training, the local government should develop two training programs. One may be called the physician exam preparation program (ProgramI), focusing on helping non-certified (assistant) physicians pass the exam, while the other may be called the rural practice focus program (ProgramII), focusing on improving the practical skills of village doctors. As shown in Table 9, only rural doctors who are potential physicians should participate in ProgramI. Those rural doctors who do not want to obtain licensure to become certified (assistant) physicians do not need to participate in the exam preparation program (ProgramI).
ProgramIwill be more likely to be implemented effectively if the following issues are addressed. First, based on the fact that only $3.13 \%$ stated that they could afford up to 2000 yuan for the training, the government should reduce out-of-pocket fees for the training to encourage more participants among village health clinic workers. Second, new educational models, including an online delivery model, needs to be developed and integrated into the educational program. This will accommodate village doctors who are too busy to participate in the face-toface training. Third, the government may use some indicators, such as education level, age, professional skill, and willingness to learn, to identify potential physicians.

ProgramII aims to improve all types of village doctors' skills to deal with emergent medical conditions, which is included in village doctor training in other countries. Tolhurst and colleagues report that rural doctors in Australia need more training related to emergency medicine [28]. Furthermore, such training should be responsive to the fact that some emergencies, such as pesticide poisoning and dog bites, are rare in urban areas but more common in rural areas in China [29, 30].

\section{Limitations}

This study had some limitations. First, it relies on self-reported data, and recall bias might exist, in particular when information about the licensure exam and participation in the training program is being collected. Second, the field survey was only conducted in Changzhou city in eastern China, which limits the generalizability of our findings. Third, we only collected the subjective attitudes of the village doctors; more objective information such as the village doctors' licensure exam score was not collected.

$$
\begin{aligned}
& \begin{array}{|l|l}
\hline \text { What is already known: } & \text { What this study adds: }
\end{array} \\
& \checkmark \text { Many studies show low } \\
& \text { quality of health } \\
& \text { services provided by } \\
& \text { village doctors. } \\
& \checkmark \text { Some studies are } \\
& \text { focused on shortage of } \\
& \text { and ageing in village } \\
& \text { doctors. } \\
& \checkmark \text { Very few studies are on } \\
& \text { exam-targeted training. } \\
& \checkmark \text { This study shows low percentage of } \\
& \text { certified (assistant) physicians based } \\
& \text { on national statistics and field survey } \\
& \text { data in Changzhou. } \\
& \text { This study shows the status of } \\
& \text { participation of exam-targeted } \\
& \text { training and out-of-pocket } \\
& \text { expenditures. } \\
& \text { This study provides suggestions on } \\
& \text { the content and methods of training } \\
& \text { of the village doctors. }
\end{aligned}
$$

Fig. 2 Health workforce in village health clinics 
Table 9 Different kinds of village doctors and needed training programs

\begin{tabular}{lll}
\hline Village doctors & $\begin{array}{l}\text { Exam preparation } \\
\text { program (Program) }\end{array}$ & $\begin{array}{l}\text { Rural practice focus } \\
\text { program (Program II) }\end{array}$ \\
\hline Certified (assistant) physician & $\times$ & $\sqrt{ }$ \\
Rural doctors & $\sqrt{ }$ & $\sqrt{ }$ \\
- potential physician & & $\sqrt{ }$ \\
Rural doctors & $\times$ & \\
- non-potential physician & & $\sqrt{ }$ \\
Health workers & $\times$ & \\
\hline
\end{tabular}

\section{Conclusions}

Although the licensure exam preparation training for certified (assistant) physicians is provided to increase the exam's passing rate, the current model has had only limited success. Therefore, a dual training program model to fit the needs of different types of village doctors is more likely to be effective. The exam-preparation program fits for rural doctors who can potentially become certified (assistant) physicians, whereas the rural practice targeted program may fit well for all types of the village doctors. Measures for optimizing the first program include more carefully identifying potential certified (assistant) physicians among rural doctors, reducing the out-of-pocket training fees and developing online training modules.

\section{Additional file}

Additional file 1: Questionnaire of village doctors in Changzhou. (DOCX $24 \mathrm{~kb})$

\section{Acknowledgements}

We wish to thank Mrs. Ya Xue, Changzhou Center for Disease Prevention and Control, Changzhou, China, for helping the organization of investigation. We also are very grateful to all the village doctors for giving their time to participate in the study.

\section{Funding}

This work was supported by the National Natural Science Foundation of China $(71573049,71373051,71573053)$, the Doctoral Fund of the Ministry of Education of China (20120071110054), and Health Research Projects from the Health Department of Jiangsu Province (H201044). None of the funding bodies played any role in the design of the study and collection, analysis and interpretation of data, and in writing the manuscript.

\section{Availability of data and materials}

The datasets are available from the corresponding author on reasonable request.

\section{Authors' contributions}

$\mathrm{XL}$ participated in design, data analysis and interpretation, and manuscript draft. JS participated in design, data interpretation, and manuscript draft revision. FY and CJ participated in design and concept of study and in data acquisition. FC and FH participated in data analysis and interpretation as well as manuscript revision. $J L$ was the principle investigator, participating in the design and concept of the study, data acquisition and supervision. All authors read and approved the final manuscript.

\section{Ethics approval and consent to participate}

This study obtained ethical approval (IRB \#09-03-0158) from the Medical Research Ethics Committee, School of Public Health, Fudan University (IRB00002408 \& FWA00002399). Completion of the survey was considered implied consent to participate.

\section{Competing interests}

The authors declare that they have no competing interests.

\section{Publisher's Note}

Springer Nature remains neutral with regard to jurisdictional claims in published maps and institutional affiliations.

\section{Author details}

${ }^{1}$ Department of Health Policy and Management, China Research Center On Disability, Innovation Center for Social Risk Governance in Health, School of Public Health, Fudan University, P.O. Box 177, 130 Dong'an Road, Shanghai 200032, China. ${ }^{2}$ Department of Health Care Administration and Policy, University of Nevada at Las Vegas, Las Vegas, USA. ${ }^{3}$ Changzhou Center for Disease Prevention and Control, Changzhou, China. ${ }^{4}$ Changzhou Commission of Health and Family Planning, Changzhou, China.

Received: 6 February 2017 Accepted: 27 April 2018

Published online: 11 May 2018

\section{References}

1. People's Republic of China State Council. Rural Doctor Practice Regulation. 2003.http://www.gov.cn/gongbao/content/2003/content_62342.htm. Accessed 5 May 2016

2. Li H, Li X, Hao C, Lu J, Xue Y, Chen M, Xu H, Zhang Y, Hao M. Residents acceptance of basic public health services offered by community health care institutions in Changzhou. Chin Gen Pract. 2012;15(8A):2570-3. https:// doi.org/10.3969/j.issn.1007-9572.2012.08.027

3. Gu X, Tang S, Cao S. The financing and organization of health services in poor rural China: a case study in Donglan County. Int J Health Plann Manage. 1995:10:265-82.

4. World Health Organization. Health workforce 2030. 2014. http://www.who int/hrh/documents/strategy_brochure2014/en/. Accessed 3 Aug 2016.

5. National Health and Family Planning Commission of the People's Republic of China. National Health and Family Planning Health Statistical Yearbook 2015. Beijing: Pecking Union Medical College Press; 2015.

6. Fang $S, T a o Y$, Ren R. The history and current situation of village doctors in China. Beijing: People's Medical Publishing House; 2006.

7. The People's Republic of China. Law on Physicians. 1998. http://www.gov. cn/banshi/2005-08/01/content 18970.htm. Accessed 18 May 2016.

8. Ministry of Health of the People's Republic of China. National Rural Doctor Education Plan (2010-2020). 2013. http://www.moh.gov.cn/qijys/s3593/ 201310/a01af8848c7f4ae081985ff4744461ee.shtml. Accessed 18 May 2016.

9. Clayton S, Yang H, Guan J, Lin Z, Wang R. Hepatitis B control in China: knowledge and practices among village doctors. Am J Public Health. 1993:83:1685-8.

10. Reynolds L, McKee M. Factors influencing antibiotic prescribing in China: an exploratory analysis. Health Policy. 2009;90(1):32-6. https://doi.org/10.1016/j. healthpol.2008.09.002

11. Dong L, Wang D, Gao J, Yan H. Doctor's injection prescribing and its correlates in village health clinics across 10 provinces of western China. J Public Health. 2011;33(4):565-70. https://doi.org/10.1093/pubmed/fdr019.

12. Sun Q, Dyar OJ, Zhao L, Tomson G, Nilsson LE, Grape M, Song Y, Yan L, Stalsby Lundborg C. Overuse of antibiotics for the common cold-attitudes and behaviors among doctors in rural areas of Shandong Province, China. BMC Pharmacol Toxicol. 2015;16:6. https://doi.org/10.1186/s40360-015-0009-x.

13. Li X, Chongsuvivatwong V, Xia X, Sangsupawanich P, Zheng W, Ma K. Revisiting current "barefoot doctors" in border areas of China: system of services, financial issue and clinical practice prior to introducing integrated management of childhood illness (IMCI). BMC Public Health. 2012:12:620. https://doi.org/10.1186/1471-2458-12-620.

14. Gan J, Zhu H, Shi J, Wang C, Lu C. The effect of training of practitioners examination. New West J. 2014;10:63-4.

15. Tang $X$, Wang J, Chen J, Zhao J, Yuan $Y$. The significance of training of practicing physician qualification examination in medical students. China 
Higher Med Educ. 2013;(10):28-9. https://doi.org/10.3969/j.issn.1002-1701. 2013.10.015.

16. Li X, Liu J, Huang J, Qian Y, Che L. An analysis of the current educational status and future training needs of China's rural doctors in 2011. Postgrad Med J. 2013;89:202-8. https://doi.org/10.1136/postgradmedj-2012-131094.

17. Zhang Z, Zhan X, Li Y, Hu R, Yan W. Web-based training for primary healthcare Workers in Rural China: a qualitative exploration of stakeholders' perceptions. PLoS One. 2015;10(5):e0125975. https://doi.org/10.1371/journal. pone.0125975

18. Li X, Cochran C, Lu J, Shen J, Hao C, Wang Y, Sun M, Li C, Chang F, Hao M. Understanding the shortage of village doctors in China and solutions under the policy of basic public health service equalization: evidence from Changzhou. Int J Health Plann Manag. 2014;30(1):E42-55. https://doi.org/10. 1002/hpm.2258.

19. National Bureau of Statistics of China. China statistical yearbook 2015. Beijing: China Statistics Press; 2015.

20. Jiangsu Statistics Bureau. Jiangsu statistical yearbook 2015. Beijing: China Statistics Press; 2015.

21. Butterworth $K$, Hayes B, Neupane B. Retention of general practitioners in rural Nepal: a qualitative study. Aust J Rural Health. 2008;16(4):201-6. https:// doi.org/10.1111/j.1440-1584.2008. 00976.x.

22. Wang J, Su J, Zuo H, Jia M, Zeng Z. What interventions do rural doctors think will increase recruitment in rural areas: a survey of 2778 health workers in Beijing. Hum Resour Health. 2013; https:/doi.org/10.1186/1478-4491-11-40.

23. Xu H, Zhang W, Gu L, Qu Z, Sa Z, Zhang X, Tian D. Aging village doctors in five counties in rural China: situation and implications. Hum Resour Health. 2014;12:36. https://doi.org/10.1186/1478-4491-12-36.

24. The Government of Zhejiang Province. Plan of further improving rural doctors. 2015. http://zfxxgk.zj.gov.cn/xxgk/jcms_files/jcms1/web57/site/art/ 2015/10/23/art_9503_80104.html. Accessed 6 Aug 2016.

25. The Government of Jiangsu Province. Plan of further strengthening village doctors and exploring innovative mechanisms of culturing basic health personnel. 2015. http://www.jiangsu.gov.cn/art/2015/4/23/art_46144_ 2545338.html. Accessed 8 May 2018.

26. The Government of Shanxi Province. Plan of further improving the village doctors. 2015. http://www.shanxi.gov.cn/yw/sxyw/201509/t20150928_99075. shtml. Accessed 8 May 2018

27. The Government of Jiangxi Province. Plan of further improving the village doctors. 2015. http:/www.jiangxi.gov.cn/zzc/azt/rc/201608/t20160815_ 1282668.htm. Accessed 8 May 2018

28. Tolhurst $\mathrm{H}$, McMillan J, Mclnerney P, Bernasconi J. The emergency medicine training needs of rural general practitioners. Aust J Rural Health. 1999;7(2):90-6.

29. Wang J. First aid nursing of acute organic phosphorus pesticide poisoning in grass roots hospital. Chin Community Doctors. 2016;32(19):163-5. https:// doi.org/10.3969/j.issn.1007-614x.2016.19.104.

30. Zhu G, Wang X. Investigation on the current situation in rural residents have dogs and health education strategies. J Anhui Agric Sci. 2015;43(2):77-8. https://doi.org/10.13989/j.cnki.0517-6611.2015.02.032.

\section{Ready to submit your research? Choose BMC and benefit from:}

- fast, convenient online submission

- thorough peer review by experienced researchers in your field

- rapid publication on acceptance

- support for research data, including large and complex data types

- gold Open Access which fosters wider collaboration and increased citations

- maximum visibility for your research: over $100 \mathrm{M}$ website views per year

At BMC, research is always in progress.

Learn more biomedcentral.com/submissions 